\title{
Neurological Aspects of SARS-CoV-2 Infection: Mechanisms and Manifestations
}

\author{
Parménides Guadarrama-Ortiz ${ }^{1 *}$, José Alberto Choreño-Parra ${ }^{1,2}$, \\ Claudia Marisol Sánchez-Martínez ${ }^{1}$, Francisco Javier Pacheco-Sánchez ${ }^{3,4}$, \\ Alberto Iván Rodríguez-Nava ${ }^{3,4}$ and Gabriela García-Quintero ${ }^{3,4}$
}

${ }^{1}$ Departament of Neurosurgery, Centro Especializado en Neurocirugía y Neurociencias México (CENNM), Mexico City, Mexico, ${ }^{2}$ Escuela Nacional de Ciencias Biológicas, Instituto Politécnico Nacional, Mexico City, Mexico, ${ }^{3}$ Internado Medico de Pregrado, Centro Especializado en Neurocirugía y Neurociencias México (CENNM), Mexico City, Mexico, ${ }^{4}$ Escuela Nacional de Medicina y Homeopatía, Instituto Politécnico Nacional, Mexico City, Mexico

OPEN ACCESS

Edited by:

Jordi A. Matias-Guiu, Servicio de Neurología, Hospital

Clínico San Carlos, Spain

Reviewed by:

Abdul Mannan Baig,

Aga Khan University, Pakistan Vanesa Pytel,

San Carlos University Clinical Hospital, Spain

Jiawei Wang,

Beijing Tongren Hospital, Capital Medical University, China

${ }^{*}$ Correspondence:

Parménides Guadarrama-Ortiz investigacion.cientifica@cennm.com; dr.guadarrama.ortiz@cennm.com

Specialty section

This article was submitted to Neuroinfectious Diseases,

a section of the journal

Frontiers in Neurology

Received: 22 April 2020

Accepted: 10 August 2020

Published: 04 September 2020

Citation: Guadarrama-Ortiz $P$ Choreño-Parra JA Sánchez-Martínez CM, Pacheco-Sánchez FJ,

Rodríguez-Nava Al and

García-Quintero G (2020) Neurological Aspects of SARS-CoV-2 Infection: Mechanisms and Manifestations.

Front. Neurol. 11:1039.

doi: 10.3389/fneur.2020.01039
The human infection of the novel severe acute respiratory syndrome coronavirus 2 (SARS-CoV-2) is a public health emergency of international concern that has caused more than 16.8 million new cases and 662,000 deaths as of July 30, 2020. Although coronavirus disease 2019 (COVID-19), which is associated with this virus, mainly affects the lungs, recent evidence from clinical and pathological studies indicates that this pathogen has a broad infective ability to spread to extrapulmonary tissues, causing multiorgan failure in severely ill patients. In this regard, there is increasing preoccupation with the neuroinvasive potential of SARS-CoV-2 due to the observation of neurological manifestations in COVID-19 patients. This concern is also supported by the neurotropism previously documented in other human coronaviruses, including the 2002-2003 SARS-CoV-1 outbreak. Hence, in the current review article, we aimed to summarize the spectrum of neurological findings associated with COVID-19, which include signs of peripheral neuropathy, myopathy, olfactory dysfunction, meningoencephalitis, Guillain-Barré syndrome, and neuropsychiatric disorders. Furthermore, we analyze the mechanisms underlying such neurological sequela and discuss possible therapeutics for patients with neurological findings associated with COVID-19. Finally, we describe the host- and pathogen-specific factors that determine the tissue tropism of SARS-CoV-2 and possible routes employed by the virus to invade the nervous system from a pathophysiological and molecular perspective. In this manner, the current manuscript contributes to increasing the current understanding of the neurological aspects of COVID-19 and the impact of the current pandemic on the neurology field.

Keywords: coronavirus, COVID-19, SARS-CoV-2, severe acute respiratory syndrome, pneumonia

\section{INTRODUCTION}

The novel severe acute respiratory syndrome coronavirus 2 (SARS-CoV-2) originated in Wuhan, China (1), in December 2019, and it has engulfed the world in an unprecedented global pandemic. The coronavirus disease 2019 (COVID-19) associated with this virus has caused more than 16.8 million new cases and 662,000 deaths as of July 30, 2020 (2), generating a high burden of disease that has exceeded the assistance capacities of several healthcare systems 
around the world. The clinical characteristics of patients with COVID-19 are similar to those observed during the outbreak of SARS-CoV-1, which emerged in 2002-2003, causing more than 8,000 confirmed cases and $\sim 800$ deaths (3). As such, the human infection with SARS-CoV-2 mainly affects the lower respiratory tract, causing mild to moderate respiratory symptoms in about $85 \%$ of patients with COVID-19 (4-6), including fever, headache, fatigue, myalgia, dry cough, and diarrhea. Most symptomatic individuals are men in their fifth and sixth decades of life that attend medical centers after an incubation period of about 4 to 5 days (4-7). Another $15 \%$ of patients present moderately severe forms of the disease manifested as pneumonia of atypical features in radiological studies of the lung, such as bilateral multi-lobe consolidations and ground-glass opacities (8). Finally, in 5 to $30 \%$ of COVID-19 patients, the virus causes severe acute respiratory syndrome (SARS), which is characterized by profound respiratory distress that obligates the establishment of intensive life support interventions, such as intubation and mechanical ventilation (4-6). Initial reports estimated mortality rates of about 2 to $4 \%$. However, new analyses indicate a higher lethality of COVID-19 (9), especially among individuals older than 65 years, and patients with comorbidities (4-6). Unfortunately, the risk of a fatal outcome is disproportionally higher among patients requiring mechanical ventilation, with a mortality rate close to $80 \%$ (7).

The rapid transmission of SARS-CoV-2 and the increasing number of positive cases reported around the world have overcome the resources of the healthcare systems in different regions. This has significantly impacted all areas of medicine, especially those directly related to the management of severe respiratory infections, such as pneumology and critical care medicine. Nonetheless, SARS-CoV-2 has the potential to spread to different extrapulmonary tissues, and, in some of the most severe cases, the infection can progress to multiorgan failure (5). Therefore, all healthcare providers from any area of medicine must acquire adequate knowledge of the principal characteristics of COVID-19. Currently, there is increasing preoccupation about the potential capacity of SARS-CoV-2 to invade the central nervous system (CNS) and the peripheral nervous system (PNS). These concerns are based on recent observations in individuals infected with SARS-CoV-2 that present neurological findings (10). A better understanding of the mechanisms underlying the neurologic sequela of patients with COVID-19 is urgent to discover novel targets for therapeutics development. In the current review article, we therefore provide an overview of the spectrum of neurological manifestations of COVID-19. Additionally, we analyze host- and pathogen-specific factors that determine the tissue tropism of SARS-CoV-2 and discuss the possible routes employed by the virus to invade the nervous system. Furthermore, we propose possible therapeutics for the neurologic complications of COVID-19.

\section{SARS-COV-2 BIOLOGY}

\section{Virology}

SARS-CoV-2 is a novel member of the group of human coronaviruses (HCoVs), which is constituted of $\mathrm{HCoV}-229 \mathrm{E}$,
HCoV-NL63, HCoV-HKU1, HCoV-OC43, SARS-CoV, and MERS-CoV (11). These are RNA single-stranded viruses belonging to the Coronaviridae family. Some of these pathogens have caused a variety of respiratory diseases in the past. For instance, SARS-CoV-1 infected more than 8,000 individuals around the world (3). Also, the human coronavirus related to the respiratory syndrome of the Middle East (MERS-CoV), which emerged in Saudi Arabia in 2012 and caused high mortality rates among infected people $(12,13)$.

Based on sequence comparisons of viral genomes, $\mathrm{HCoVs}$ are grouped into four genera: alpha, beta, gamma, and delta coronaviruses. SARS-CoV-2 is a beta coronavirus genetically related to another bat coronavirus named BatCoV RaTG13 as well as SARS-CoV-1 $(14,15)$. Furthermore, SARS-CoV-2 also shares its genetic identity with coronaviruses isolated from pangolins $(16,17)$. Hence, it is believed that COVID-19 is a zoonotic disease that originated from bats or pangolins. The genome of SARS-CoV-2 consists of a single RNA strand of 29.903 bp that codifies for the replicase-transcriptase, as well as for the structural proteins spike (S), envelope (E), membrane (M), and nucleocapsid (N) (15).

\section{Mechanism of Infection and Determinants of SARS-CoV-2 Tropism}

The initial step of SARS-CoV-2 infection is the recognition of its receptors on the surface of host cells. This step is mediated by the viral spike (S) protein, which recognizes the human receptor angiotensin I-converting enzyme 2 (ACE2), the same receptor for the S protein of SARS-CoV-1 (18-20). This protein owns two functional domains: the $S 1$ domain contains the receptorbinding domain (RBD), which attaches to ACE2, whereas the S2 domain mediates the fusion of the viral and host cell membranes (20). Therefore, the organ distribution of the ACE2 receptor is a crucial determinant of the virus infectivity and tropism. A second step determinant in the infection process of SARS-CoV-2 is the activation of the $\mathrm{S}$ protein. This process is mediated by different host proteases, which execute the cleavage of the molecule at the S1/S2 and S'2 sites. This protein processing allows the complete activity of the S2 domain and the fusion of the viral and cellular membranes. For this purpose, and as in the case of SARS-CoV-1, SARS-CoV-2 uses the transmembrane serine protease 2 (TMPRSS2) $(19,21,22)$. Interestingly, the proteases TMPRSS4 and cathepsin L also promote SARSCoV-2 infection of human small intestinal enterocytes and 293/hACE2 cells (23, 24). Hence, the tissue patterns of expression of TMPRSS2, TMPRSS4, and cathepsin L is another decisive factor that determines the tropism of the virus, and, indeed, some drugs that inhibit the activity of these proteases are now proposed as potential therapeutic agents to prevent and treat COVID-19 $(19,23)$.

Other factors implicated in the process of SARS-CoV-2 infection include the phosphatidylinositol 3-phosphate 5kinase (PIKfyve) (23). This enzyme mediates the production of phosphatidylinositol-3,5-bisphosphate [PI(3,5)P2], a phosphoinositide that participates in the maturation process of endosomes. Treatment with apilimod, a potent inhibitor for 


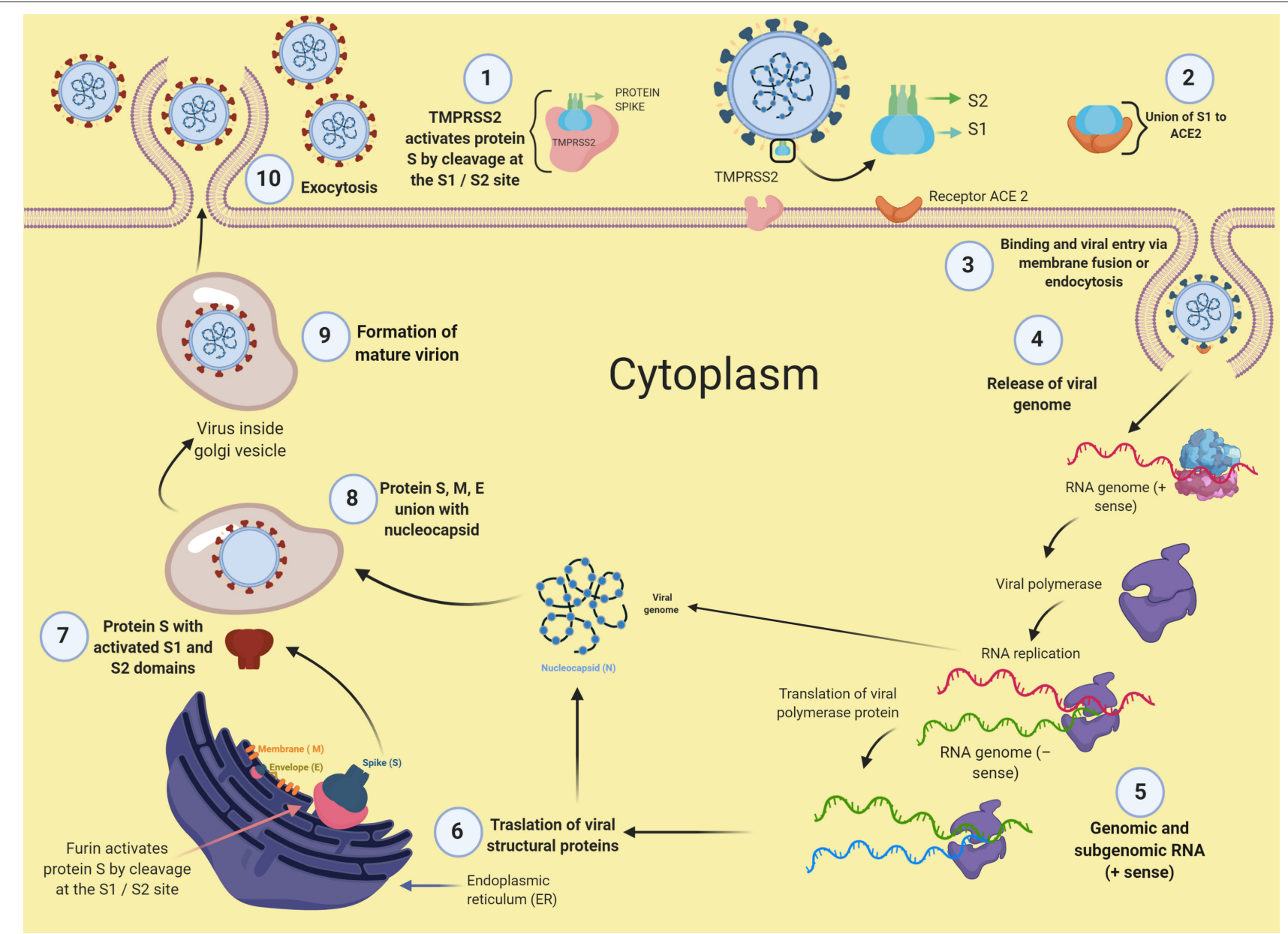

FIGURE 1 | Mechanisms of infection of SARS-CoV-2. This figure was created with BioRender.

PIKfyve, reduced the infectivity of SARS-CoV-2 and could be a novel candidate for therapeutic applications. After the entry into host cells, viral replication begins with the translation of the replicase-polymerase gene and the assembly of the replication-transcription complex. This complex subsequently transcribes the genomic regions that codify for structural proteins. New virions are assembled in the endoplasmic reticulum and Golgi apparatus to finally egress from the cell (11). A particular feature of SARS-CoV-2 is that it possesses a polybasic furin cleavage sequence (PRRA) in the S1/S2 site, which is absent in other close related coronaviruses $(14,20)$. This inserted furin cleavage sequence is processed at the Golgi apparatus during the biosynthesis of the $S$ protein of novel virions inside the host infected cells (20). The novel virions of SARS-CoV-2 may thus contain an S protein primed and ready to infect any other cells expressing the ACE2 receptor, with no further requirement of TMPRSS2 activity. As virtually all cells express furin under normal conditions, the inserted furin cleavage sequence may expand the transmissibility and tissue tropism of SARS-CoV-2. Figure 1 illustrates the process of SARS-CoV-2 infection.

\section{The Immune Response Against SARS-CoV-2}

SARS-CoV-2 elicits an exuberant immune response characterized by a dysregulated production of soluble immune mediators. This phenomenon has been called a "cytokine storm" and is responsible for mediating tissue damage in patients with COVID-19 that progress to severe illness (25-28). The immune receptors that recognize the viral infection and initiate the immune responses against SARS-CoV-2 are unknown. As this virus is genetically related to SARS-CoV-1, it is presumed that both viruses share mechanisms of infection. In this sense, SARS-CoV-1 is recognized by the toll-like receptors (TLR) TLR3 and TLR4, which induce an immune reaction via MyD88 and TRIF pathways $(29,30)$. Furthermore, SARS-CoV-1 triggers the production of IL- $1 \beta$ through the activation of the inflammasome (31). In this regard, the activation of the inflammasome is also possible to occur during SARS-CoV-2 infection, as high levels of IL-1 $\beta$ have been observed in COVID-19 patients (32). Other immune mediators that are exaggeratedly produced in response to SARS-CoV-2 include IL2, IL-6, IL7, IL10, G-SCF, CXCL10, MCP-1, MIP-1A, and TNF $\alpha(5,28,33)$. From these, IL-1 $\beta$, IL-6, 
CXCL10, and TNF $\alpha$ are the cytokines with a higher capacity to generate tissue damage in several organs, including the CNS, due to their pro-inflammatory properties. For instance, IL-1 $\beta$ and IL- 6 have been implicated in neurotoxicity associated with chimeric antigen receptor (CAR) T cell therapy in patients with hematological malignancies $(34,35)$. These cytokines possess detrimental effects on endothelial function at several vascular niches, which may be implicated in the pathophysiology of the neurological complications of COVID-19, as discussed later.

Notably, despite the dysregulated production of immune mediators, an ample range of immune cell subtypes are depleted from the circulation of patients with severe SARS-CoV-2 infection. These cells include monocytes, dendritic cells, CD4+ and CD8+ T cells, and NK cells (36). Furthermore, the few adaptive lymphocytes that remain in the blood express markers of functional exhaustion (37). These data suggest that severe COVID-19 is a state of immunosuppression similar to the known sepsis-induced immunosuppression (38). However, it is also possible that the robust recruitment of functional immune cells to the sites of SARS-CoV-2 infection may explain the leukopenia observed during COVID-19.

\section{MECHANISM OF SARS-COV-2 ENTRY INTO THE CNS}

\section{Expression of SARS-CoV-2 Viral Entry Factors in the CNS}

Several HCoVs, including SARS-CoV-1, have the potential to infect different human tissues and organs $(39,40)$. Similarly, SARS-CoV-2 may also spread to several extrapulmonary tissues, including the CNS. Although recent analyses of autopsy specimens from patients with COVID-19 have not explored the presence of this virus in the brain (41), the neurological manifestations observed among individuals with COVID-19 (10) and the isolation of other human coronaviruses from neurological specimens support the notion of a possible neurotropism of SARS-CoV-2 (42-47). The neurotropism of other HCoVs has been extensively revised elsewhere (48).

As mentioned before, the patterns of expression of ACE2, TMPRSS2, TMPRSS4, furin, cathepsin L, and other entry factors used by SARS-CoV-2 for infection determine the tropism of the virus. The ACE2 receptor is highly expressed in cells of the alveolar epithelium $(49,50)$, which explains the vulnerability of the lungs to infection. The expression of ACE2 has also been found in other tissues, including the oral mucosa, endothelium, heart, kidney, lymphoid organs, testis, gut, and urinary tract (4952). Nonetheless, distribution of TMPRSS2 has been assessed in a limited variety of human tissues, showing high expression in prostate cells, respiratory epithelial cells, salivary gland, kidney, liver, stomach, small intestine, and colon (53-55). TMPRSS2 is regulated by androgens (53), which may explain the higher susceptibility of men to suffer from severe forms of COVID19. Few studies have analyzed the expression of TMPRSS4 and cathepsin L in healthy human organs. According to the Human Protein Atlas (https://www.proteinatlas.org/) dataset, TMPRSS4 is present in the cerebral cortex, hippocampus, caudate, thyroid gland, adrenal gland, nasopharynx, bronchi, lung, stomach, duodenum, colon, rectum, gallbladder, pancreas, and genitourinary tract. Meanwhile, cathepsin L shows medium expression in lung and liver, and low expression at bronchi, salivary gland, liver, kidney, pancreas, and genitourinary tract.

The expression in the human body of the known genes mediating the entry of SARS-CoV-2 into human cells coincides with the multiorgan pattern of COVID-19 manifestations. Nonetheless, the presence of such factors is low in the CNS under normal conditions. This may be in part because previous studies have only analyzed the bulk organ gene expression patterns of ACE2 and TMPRSS2. More recently, a comprehensive analysis of several single-cell RNA-seq databases showed that there are dual-positive ACE2+TMPRSS2+ cells in tissues beyond the respiratory system, including oligodendrocytes in the brain, and inhibitory enteric neurons (56). Furthermore, ACE2+CTSL+ cells were enriched in the olfactory epithelium. These data support some of the possible routes of SARS-CoV-2 entry into the CNS discussed below.

\section{Routes of SARS-CoV-2 Entry Into the CNS}

The mechanisms employed by SARS-CoV-2 to infect the nervous system are unknown. Currently, the hypotheses about the routes of viral entry into the CNS rely on previous observations made in experimental studies of SARS-CoV-1 infection. One hypothesis proposes that SARS-CoV-2 invades the brain by breaching the blood-brain barrier (BBB). Evidence in favor of this infection mechanism includes the high expression of the ACE2 receptor in endothelial cells of blood vessels $(49,50)$. The virus may therefore infect endothelial cells of the brain vasculature in the first term, and it may then spread to the surrounding ACE2+TMPRSS2+ oligodendrocytes and, finally, to the neurons. This would explain why SARS-CoV-1 has been observed inside neurons even when they have a mild expression of ACE2 under normal conditions $(39,40,57)$. Despite this, SARS-CoV-1 has not been isolated from or observed inside endothelial cells (58). Conversely, the high concentrations of pro-inflammatory cytokines in the systemic circulation of patients with severe forms of COVID-19 might induce structural and functional alterations of the $\operatorname{BBB}(5,28$, 59). In this sense, it is well-known that different inflammatory mediators have detrimental effects on BBB integrity, increasing its permeability to neurotoxic molecules and immune cells (60). SARS-CoV-2 could thus gain access to the CNS directly through a paracellular route or within the immune cells, a mechanism that has been called a "trojan horse"(61). It might be feasible for this mechanism to occur during SARS-CoV-2 infection since the previous SARS-CoV-1 has also been observed inside different leukocyte subsets (40).

Secondly, the virus could enter the CNS through the olfactory epithelium, crossing the cribriform plate of the ethmoid bone and reaching the olfactory bulb from which it could spread to different areas of the brain (62). This route was demonstrated in mice intranasally inoculated with SARS-CoV-1, among which a rapid viral spread from the olfactory bulb to the brain stem was observed. This exposure to the virus caused high lethality among infected animals due to the occurrence of neuronal death in the respiratory centers of the brain stem (63). 
Similar results were observed in another animal model of CNS infection with the HCoV-OC43 coronavirus (64). In humans, some studies demonstrated olfactory neuropathy in patients with SARS-CoV-1 infection (65). Likewise, recent investigations have shown that the olfactory epithelium is enriched with ACE2+CTSL+ cells (56). Moreover, hyposmia and anosmia are frequent manifestations of COVID-19 $(10,66)$, suggesting that SARS-CoV-2 might also infect the olfactory bulb in COVID-19 patients. In light of these findings, some researchers have proposed that the neuroinvasive potential of SARS-CoV-2 could contribute to the respiratory failure observed in patients with severe COVID-19 (67).

Finally, as in the case of other respiratory viruses with neurotropic potential, including the influenza A virus (68), SARS-CoV-2 could gain access to the CNS through the vagus nerve. The terminals of this nerve are located along the respiratory and gastrointestinal tracts, sites with high expression of ACE2 $(49,50)$ and enriched with ACE2+TMPRSS2+ enteric neurons (56). From these organs, the virus could gain access to the brain stem, taking advantage of the polarization of neurons and the machinery responsible for retrograde neuronal communication, or through endocytosis and clathrin-mediated exocytosis, as observed in the case of the transsynaptic transmission of the porcine coronavirus HEV 67N (69). The possible CNS invasion routes used by SARS-CoV-2 are illustrated in Figure 2.

\section{NEUROLOGICAL MANIFESTATIONS OF COVID-19 DUE TO CNS INVOLVEMENT}

\section{Non-specific Neurological Symptoms}

Some of the initial descriptions of the clinical phenotype of patients infected with SARS-CoV-2 showed that up to $10 \%$ of individuals with COVID-19 manifested non-specific neurological symptoms such as headache and dizziness (5, $6,70)$. In a more recent report by Mao et al., a third of patients with COVID-19 presented non-specific neurological manifestations, including dizziness $(16.8 \%)$, headache $(13.1 \%)$, loss of consciousness (7.5\%), and seizures (0.5\%) (10). Two recent systematic reviews and meta-analyses showed that headache and dizziness are among the most frequent neurological symptoms affecting COVID-19 patients $(71,72)$. Interestingly, headache can occur even in the absence of fever and can be manifested as a migraine, tension-type, or cluster headache (73).

These non-specific neurological symptoms may reflect the neurotoxic effect of hypoxemia and the cytokine storm observed in patients with severe COVID-19. However, some of these manifestations must be differentiated from delirium, and other secondary causes, such as metabolic, gastrointestinal, renal, and hematological complications, must be ruled out, particularly in aged patients with underlying comorbidities. Interestingly, non-specific neurological manifestations are more frequent in patients who progress to respiratory failure, which supports the hypothesis about a possible contribution of the CNS infection to the respiratory failure caused by SARS-CoV-2 (67). Furthermore, patients with unspecific neurological symptoms have shown higher degrees of leukopenia, thrombocytopenia, and elevated blood urea nitrogen levels (BUN) (10). These data suggest that some of these findings might have certain prognostic value to predict the occurrence of more severe neurological complications. However, the predictive potential of non-specific neurological symptoms needs to be further evaluated in prospective studies. This would be of great help for the timely detection of patients at risk of neurologic sequela.

\section{COVID-19 Associated Meningitis, Encephalitis, and Acute Necrotizing Encephalopathy}

Acute meningitis and encephalitis are dramatic complications of various viral infections that often result in high morbidity and mortality rates due to their severity. Coronaviruses have also been associated with these neurological complications in humans. For instance, the HCoV-OC43 coronavirus was isolated from the brain of a patient who died of viral encephalitis (74). Likewise, both SARS-CoV-1 (46) and MERS-CoV have been reported to cause encephalitis (75).

In this context, SARS-CoV-2 can also cause viral meningitis and encephalitis, as demonstrated by a recent report of a 64-yearold patient with laboratory-confirmed COVID-19 who presented neurologic manifestations during the infection, including lethargy, clonus, and pyramidal signs in the lower limbs as well as stiff neck and Brudzinski sign (76). The cerebrospinal fluid (CSF) study revealed high protein levels and hypoglycorrhachia, although the virus could not be isolated from CSF in this case. The patient received antiviral drugs and symptomatic measures, progressing favorably without neurological complications. Similarly, in another report, a 24-year-old man with a 3-day history of headache developed fever, loss of consciousness, and seizures (77). Upon hospital admission, he presented signs of meningeal irritation and a low Glasgow Coma Scale (GCS) score, requiring mechanical ventilation. During his medical follow-up, he continued presenting seizures resistant to pharmacological treatment. His laboratory studies revealed high protein levels and pleocytosis in the CSF, and the MRI showed hyperintensities in the mesial temporal lobe. The patient tested negative for COVID-19 when his nasopharyngeal swab specimen was analyzed. Nonetheless, the result of the test was positive in the CSF sample. This finding was the first demonstration of the presence of SARS-CoV-2 in the CNS. The occurrence of encephalitis as the initial and even only manifestation of COVID-19 has latter been reported in three additional cases from China and the United States (78-80). Finally, another case report showed that SARS-CoV-2 infection could cause acute necrotizing encephalopathy (81). This entity is a severe neurological complication resulting from the disruption of the $\mathrm{BBB}$ associated with the cytokine storm observed in individuals with a critical illness.

Together, these cases illustrate the development of severe acute neurological complications in patients with COVID-19, confirming the neurotropism of SARS-CoV-2. These findings justify the intentional search for SARS-CoV-2 infection in patients attending with acute neurological manifestations and 


\section{A}
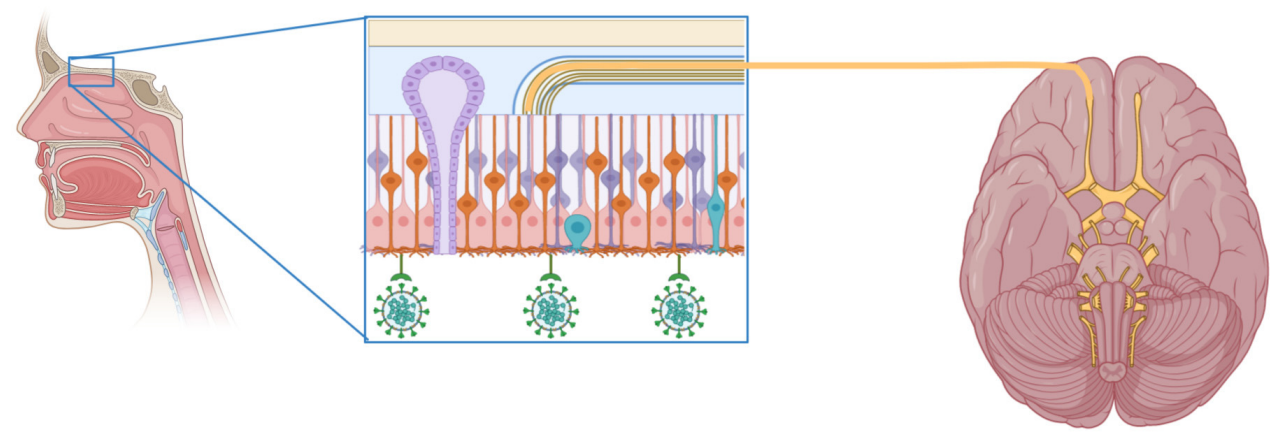

B

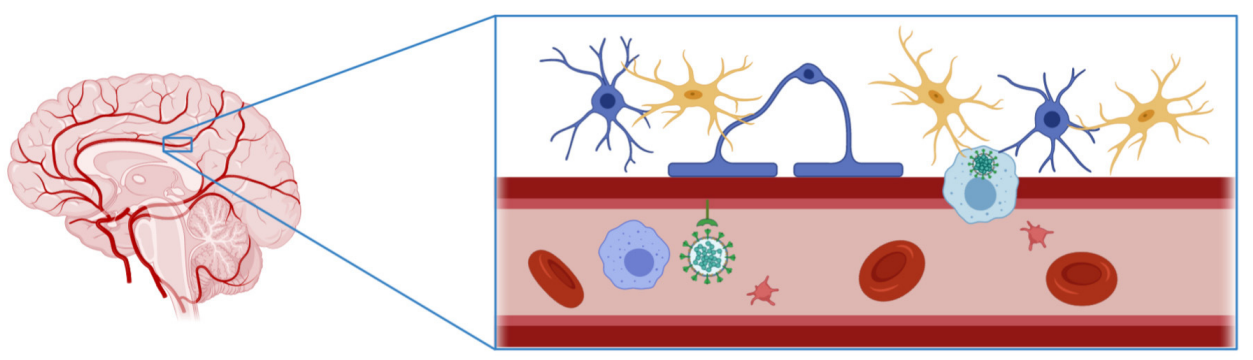

C

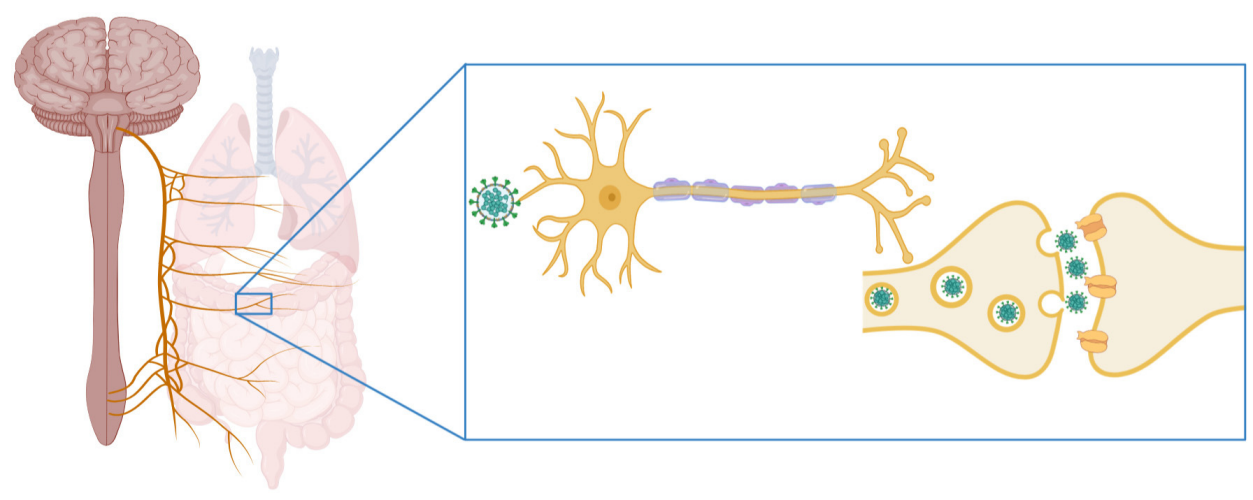

FIGURE 2 | Mechanisms of SARS-CoV-2 invasion to the central nervous system. (A) SARS-CoV-2 can enter the CNS through the olfactory bulb. Indeed, recent investigations have shown that the olfactory epithelium is enriched with cells that express the receptor ACE2 and the protease cathepsin L. (B) The virus can also infect the CNS via the hematogenous route, attaching to the ACE2 receptor expressed in endothelial cells of the cerebral blood vessels, or inside an immune cell. (C) Finally, SARS-CoV-2 can infect the nerve terminals of the vagus nerve located in the respiratory system and the gastrointestinal tract. From these sites, the virus can reach the CNS using the mechanisms of retrograde neuronal protein transport and transsynaptic transmission. This figure was created with BioRender.

febrile illness even in the absence of respiratory symptoms. The frequency and factors related to the severity of these complications need to be extensively investigated in future studies. This would require the conduction of comprehensive characterizations of genetic and immunological characteristics associated with the risk of severe neurological complications in COVID-19 patients. In addition, future studies evaluating the relationship between the temporal dynamics of neurological findings, the kinetics of viral loads in the circulation and CNS, and distinctive patterns of circulating immune mediators are warranted. This might inform about the potential of contagiousness of COVID-19 patients according to their neurological symptoms and reveal possible candidate biomarkers to distinguish individuals at high risk of severe neurologic sequela.

\section{Cerebrovascular Disease}

The antecedent of a recent respiratory infection, such as influenza, or influenza-like illness, has been related to acute cardiovascular complications, including acute myocardial infarction and stroke (82). Among infectious causes of vascular events, the infection with the varicella-zoster virus (VSV) is 
the most frequent viral cause of stroke (83). The study by Mao et al. revealed that $3 \%$ of patients with COVID-19 also present stroke as their only neurological manifestation of the infection. From these, the majority were affected by ischemic strokes (six ischemic vs. one hemorrhagic from a total of 214 patients included in the study) (10). Stroke in individuals with COVID-19 occurs late during the disease and is more frequently observed among patients with severe respiratory failure. Interestingly, some COVID-19 patients were admitted to medical centers with hemiplegia and no history of respiratory symptoms (10). Other studies have also reported stroke in patients with severe COVID19 , even among young individuals $(84,85)$. This might indicate that stroke could be a result of vascular alterations directly driven by the virus, although the presence of cardiovascular risk factors can increase the incidence of this complication. A recent meta-analysis found that stroke, apart from being a frequent complication of COVID-19, has a considerable prognostic value to predict the risk of mortality. As such, patients with stroke have a 3 -fold increase in the risk of death due to COVID-19 (86).

The association between stroke and COVID-19 might result from the critical condition and the pro-inflammatory state that prevails in most severely ill patients. The increased levels of pro-inflammatory cytokines in these individuals could alter the normal function of the cerebral vessels. These factors, along with the high prevalence of cardiovascular risk factors among patients with COVID-19, can trigger cerebrovascular complications. The endothelial infection of the cerebral vasculature due to its high expression of the ACE2 receptor might further contribute to these complications (49). In fact, the incidence of stroke in patients with VSV infection is a consequence of the invasion of the cerebral arteries by the virus (83). Other mechanisms by which SARS-CoV-2 could cause stroke include coagulation disorders. The abnormalities in the coagulation of severe COVID-19 patients have unique characteristics that partially resemble disseminated intravascular coagulation (DIC) or thrombotic microangiopathy. These alterations increase the risk of thrombotic complications and death due to COVID19 (87). Acute myocarditis has been reported in patients with SARS-CoV-2 infection $(88,89)$. This cardiac complication could trigger events of brain embolization and stroke, which might explain the incidence of cerebral infarctions in young patients with COVID-19 in the absence of cardiovascular risk factors.

\section{NEUROLOGICAL MANIFESTATIONS OF COVID-19 DUE TO PNS INVOLVEMENT}

\section{Peripheral Neuropathy and Myopathy Associated With SARS-CoV-2 Infection}

During the outbreak caused by SARS-CoV-1, some studies described the occurrence of peripheral motor neuropathy and myopathy among infected individuals, mostly as part of the spectrum of manifestations of the critical illness polyneuropathy and myopathy disorders (90). Similarly, $2.3 \%$ of patients with COVID-19 have presented neuropathic pain, probably associated with peripheral neuropathy, whereas $10.7 \%$ of the cases showed data of skeletal muscle injury with elevated serum levels of creatine phosphokinase (CPK) (10). As in the case of other neurological manifestations, neuropathic pain and myopathy have been more frequently observed in patients with severe forms of COVID-19. Notably, these symptoms occur earlier during the disease in individuals with SARS-CoV-2 infection as compared to patients affected by SARS-CoV-1 (10). This suggests that the neuropathy and myopathy of COVID-19 are directly associated with the injury of peripheral nerves and striated muscles driven by the virus. COVID-19 patients with neuropathy and myopathy, however, exhibit higher levels of neutrophils and acute phase reactants than individuals without neurological manifestations (10). The nerve and muscle disorders observed during SARS-CoV-2 infection might thus be associated with a critical illness polyneuropathy of rapid development due to the more deteriorated clinical condition of patients with COVID-19 as compared to cases of SARS-CoV-1 infection. Vascular, thrombotic, ischemic, and direct nerve and muscle alterations driven by SARS-CoV-2 can contribute to neuropathy and myopathy of COVID-19 patients.

\section{Cranial Neuropathies in Patients With COVID-19}

A wide range of infectious diseases can cause complicate within cranial neuropathies like facial palsy and ophthalmoplegia. Among the pathogens that cause these manifestations with more frequency are HIV and VSV (91). Cranial nerves might also be susceptible to a direct or indirect injury caused by SARS-CoV-2. In fact, according to a recent study, about $85 \%$ and $88 \%$ of patients with COVID-19 develop olfactory and gustatory dysfunction (66). Similarly, in another investigation conducted in Italy, about 33\% of patients with COVID-19 reported taste and/or olfactory disorders (92). These findings might be specific for SARS-CoV-2 infection and could predict the causative pathogen in patients with acute respiratory illness. Indeed, smell and/or taste disorders were more frequently observed among COVID-19 patients as compared to individuals with laboratory-confirmed influenza infection in a case-control study conducted in Spain (93). These observations might be of particular relevance for the upcoming flu season, which is predicted to be historically unique due to the convergence of influenza and COVID-19. During such an envisioned scenario, the differentiation of these diseases by clinical manifestations could be complicated. Nonetheless, the correct identification of the causative pathogen have therapeutic implications, such as the selection of adequate antiviral treatment. The presence of smell and taste dysfunction could thus be useful to distinguish COVID-19 from influenza. Furthermore, these symptoms can precede the onset of respiratory symptoms $(94,95)$, and their presence may predict a milder clinical course of the disease (96). Notably, COVID-19-related olfactory dysfunction has not been associated with rhinorrhea or nasal congestion, and more than half of the affected patients did not recover the function of the olfactory nerve (66). This suggests direct damage to the olfactory epithelium, which further reaffirms the possibility of an entry route of SARS-CoV-2 through the cribriform plate, reaching 
the olfactory bulb from where it spreads to other parts of the CNS (62).

\section{AUTOIMMUNE NEUROLOGICAL SYNDROMES ASSOCIATED WITH COVID-19}

\section{Guillain-Barré Syndrome}

The association between viral infections and Guillain-Barré syndrome has been largely described in the past (97). Infection with Campylobacter jejuni, cytomegalovirus, or Mycoplasma pneumoniae precedes Guillain-Barré syndrome in up to twothirds of affected individuals (98). More recently, several viral emerging diseases have shown this syndrome as one of its more common and severe complications, as is the case of the infection with the Zika virus (99). Although this association was not described in patients infected with SARS-CoV-1, cases of Guillain-Barré syndrome were observed during the outbreak of MERS-CoV (100). In this context, the infection with SARSCoV-2 could also complicate with or manifests as Guillain-Barré syndrome. In a recent report, Zhao et al. described the case of a woman that developed asymmetric and progressive muscle weakness in the lower limbs, associated with leukopenia and high protein levels in the CSF without pleocytosis, accompanied by data of demyelinating neuropathy in studies of nerve conduction (101). The patient had a history of a recent trip to the city of Wuhan, and she showed no evidence of respiratory system involvement at the time of symptom onset. A total of 8days later, the appearance of fever, respiratory symptoms, and radiological data compatible with pneumonia was documented, confirming the SARS-CoV-2 infection by laboratory testing in a nasopharyngeal swab sample. The patient received intravenous immunoglobulin treatment recovering the neurological function without sequel. Similarly, in another case from Italy, a 71-yearold male also developed Guillain-Barré syndrome before the onset of any respiratory symptom (102).

These reports suggest that Guillain-Barré syndrome may be the first manifestation of COVID-19, presenting as a parainfectious phenomenon. This is due to the parallel occurrence of neurological and respiratory symptoms, instead of the postinfectious pattern observed in other infections, including the MERS-CoV (100). Nonetheless, two new case reports of six COVID-19 patients demonstrated that Guillain-Barré syndrome could occur a few days after the onset of respiratory symptoms $(103,104)$. Collectively, these findings obligate physicians to continuously monitor the neurological condition of patients with suspected or confirmed SARS-CoV-2 infection to identify any sign of demyelinating neuropathy. Furthermore, the occurrence of Guillain-Barré syndrome associated with COVID-19 must be carefully distinguished from the myopathy and neuropathy disorders of the critically ill patient.

\section{Miller Fisher Syndrome}

Miller Fisher syndrome is a rare neurological disease that is considered a variant of the Guillain-Barré syndrome. This disorder is characterized by the triad of abnormal muscle coordination, paralysis of the eye muscles, and the absence of tendon reflexes. Miller Fisher syndrome can be associated with a history of recent viral illness; however, no evidence exists of its association with human coronavirus infections. Interestingly, a recent paper has reported the occurrence of the triad of ataxia, areflexia, and ophthalmoplegia in a 50-yearold man that presented cough, fever, anosmia, and hypogeusia some days before the onset of the neurological symptoms. The infection with the SARS-CoV-2 infection was confirmed in an oropharyngeal swab sample, and blood tests showed lymphopenia, elevated C-reactive protein levels, and antiGD1b-IgG antibodies. He received treatment with intravenous immunoglobulin, which caused significant improvement in his neurological functions. Collectively, the literature summarized here indicates that neurological syndromes caused by aberrant immune responses, such as Guillain-Barré and Miller Fisher syndromes, can occur as part of the clinical spectrum of SARS-CoV-2 infection. Despite this, the immune mechanisms implicated in these phenomena, and the possibility of a direct neuropathic effect driven by the virus are unknown.

Molecular mimicry has been proposed as the primary immune alteration underlying the development of Guillain-Barré syndrome during infections (105). This phenomenon is related to the presence of carbohydrates in infectious agents of similar structural characteristics as compared to carbohydrates expressed on neuronal membrane ganglioside and galactocerebrosides. For instance, the lipopolysaccharides of Campylobacter jejuni share ganglioside-like epitopes with peripheral nerves (106), whereas galactocerebroside-like structures are present in glycolipids of Mycoplasma pneumoniae (107). These molecular similarities trigger the production of anti-glycolipid antibodies, which mediate autoimmune damage to peripheral nerves. Gangliosideor galactocerebroside-like epitopes have not been described in SARS-CoV-2. However, the S protein of this virus possesses $22 \mathrm{~N}$ linked glycan sequons per promoter (20), that could potentially share certain similitude with carbohydrates localized on the surface of the host nerve cells. Future studies are required to evaluate the serologic features of anti-glycolipid antibodies in patients with COVID-19 to elucidate possible mechanisms underlying the association between SARS-CoV-2 infection and Guillain-Barré syndrome.

\section{NEUROPSYCHIATRIC MANIFESTATIONS OF COVID-19}

Several viruses affecting humans have been implicated in the development of psychiatric symptoms due to their neurotropism. The immediate antecedent for the global transmission of a respiratory pathogen was the 2009 pandemic associated with the emergence of a novel influenza A (H1N1) virus. Several neuropsychiatric manifestations during the outbreak of influenza were observed among infected patients, including fear and behavioral changes (108). Similarly, during the SARS-CoV-1, a range of psychiatric disorders was identified, including anxiety, depression, suicidal ideation, and hallucinations $(109,110)$. A recent systematic review found a high incidence of confusion, 
depression, anxiety, memory impairment, insomnia, and steroidinduced psychosis among patients with SARS-CoV-1 or MERS$\mathrm{CoV}$ infection (111). The mechanisms underlying psychiatric disorders in patients with viral infections are not precise, but they might be related to the structural and functional disruption of the BBB mediated by circulating inflammatory cytokines produced in response to viruses. These mediators might also alter neuronal networks implicated in cognitive functions. Indeed, several psychiatric illnesses, including schizophrenia, have been proposed to result from immune-mediated pathogenic mechanisms (112).

In this sense, it is clear that the current pandemic can cause indirect effects on the mental health of infected and non-infected people due to quarantine and social distancing measures, which constitute sources of distress additional to the daily life problems (113). At this moment, however, there is little literature about neuropsychiatric disorders directly associated with the infection with SARS-CoV-2. In a case series of three patients with laboratory-confirmed COVID19 and no evidence of respiratory symptoms, it was found that such individuals presented anxiety, agitation, paranoid behavior, disorganized thinking, and auditory hallucinations (114). Other authors have also reported that delirium can be present in a high percentage of COVID-19 patients (111). Thus, as mentioned before, delirium must also be considered in the differential diagnosis of individuals with acute neuropsychiatric manifestations associated with SARS-CoV-2 infection. Finally, the virus could lead to long-term neuropsychiatric and cognitive sequels. In fact, survivors of SARS-CoV-1 and MERS-CoV have been found to present depression, anxiety, and posttraumatic distress syndrome several months after the diagnosis (111). Therefore, it is essential to conduct long prospective observational studies to estimate the incidence of psychiatric disorders in the post-illness stage of COVID-19. Future studies must address possible links between the antecedent of SARS$\mathrm{CoV}-2$ infection and the incidence of chronic neurodegenerative disorders. The studies about the spectrum of neurological and psychiatric manifestations of COVID-19 are summarized in Table 1.

\section{POTENTIAL THERAPEUTICS FOR THE NEUROLOGICAL COMPLICATIONS OF SARS-COV-2 INFECTION}

Supportive measures, along with strict control and prevention of fever, high blood pressure, elevated glucose, and seizures, may ameliorate the neurotoxic potential of SARS-CoV-2 infection. Currently, there are no mechanism-based therapeutics specific for neurological complications of COVID-19. The evidence curated in this review suggests possible pathologic processes underlying the involvement of the CNS/PNS during SARS$\mathrm{CoV}-2$ infection. A better understanding of these mechanisms may reveal targets for therapeutic interventions. Direct effects driven by the virus, such as the infection of brain blood vessels and nerve cells, are proposed to play a role in neurologic manifestations of COVID-19. Although studies addressing the
TABLE 1 | The spectrum of neurological manifestations of SARS-CoV-2 infection.

\begin{tabular}{|c|c|c|c|c|}
\hline Clinical finding & $\begin{array}{l}\text { No. of } \\
\text { patients }\end{array}$ & Author & Country & References \\
\hline \multirow[t]{5}{*}{ Headache } & $3 / 39$ & Huang et al. & China & (5) \\
\hline & 9/138 & Wang et al. & China & (6) \\
\hline & $8 / 99$ & Chen et al. & China & (70) \\
\hline & $28 / 214$ & Mao et al. & China & (10) \\
\hline & 29/112 & $\begin{array}{l}\text { Porta-Etessam } \\
\text { et al. }\end{array}$ & Spain & (73) \\
\hline \multirow[t]{2}{*}{ Dizziness } & $13 / 138$ & Wang et al. & China & (6) \\
\hline & $36 / 214$ & Mao et al. & China & (10) \\
\hline \multirow{2}{*}{$\begin{array}{l}\text { Loss of } \\
\text { consciousness/ } \\
\text { altered mental status }\end{array}$} & 9/99 & Chen et al. & China & (70) \\
\hline & $16 / 214$ & Mao et al. & China & (10) \\
\hline Seizures & $1 / 214$ & Mao et al. & China & (10) \\
\hline \multirow{3}{*}{$\begin{array}{l}\text { Cerebrovascular } \\
\text { disease }\end{array}$} & $6 / 214$ & Mao et al. & China & (10) \\
\hline & $3 / 58$ & Helms et al. & France & (84) \\
\hline & 5 cases & Oxley et al. & United States & (85) \\
\hline \multirow[t]{4}{*}{$\begin{array}{l}\text { Meningitis/ } \\
\text { encephalitis }\end{array}$} & $\begin{array}{l}1 \text { case report } \\
1 \text { case report }\end{array}$ & $\begin{array}{l}\text { Moriguchi et al. } \\
\text { Yin et al. }\end{array}$ & $\begin{array}{l}\text { Japan } \\
\text { China }\end{array}$ & $\begin{array}{l}(77) \\
(76)\end{array}$ \\
\hline & 1 case report & Duong et al. & United States & (78) \\
\hline & 1 case report & Filatov et al. & United States & (79) \\
\hline & 1 case report & Ye et al. & China & (80) \\
\hline \multirow{7}{*}{$\begin{array}{l}\text { Olfactory and/or taste } \\
\text { dysfunction }\end{array}$} & 20/59 & Giacomelli et al. & Italy & (92) \\
\hline & $31 / 79$ & $\begin{array}{l}\text { Beltrán- } \\
\text { Corbellini } \\
\text { et al. }\end{array}$ & Spain & (93) \\
\hline & $128 / 169$ & Yan et al. & United States & (96) \\
\hline & $130 / 374$ & Spinato et al. & Italy & (95) \\
\hline & $357 / 417$ & Lechien et al. & Belgium & (66) \\
\hline & $23 / 214$ & Mao et al. & China & (10) \\
\hline & 2 cases & $\begin{array}{l}\text { Lorenzo Villalba } \\
\text { et al. }\end{array}$ & Spain & (94) \\
\hline $\begin{array}{l}\text { Peripheral } \\
\text { neuropathy/nerve } \\
\text { pain }\end{array}$ & $5 / 214$ & Mao et al. & China & (10) \\
\hline Myopathy & $23 / 214$ & Mao et al. & China & (10) \\
\hline \multirow[t]{3}{*}{$\begin{array}{l}\text { Guillain-Barre } \\
\text { syndrome }\end{array}$} & $\begin{array}{l}1 \text { case report } \\
1 \text { case report }\end{array}$ & $\begin{array}{l}\text { Zhao et al. } \\
\text { Alberti et al. }\end{array}$ & $\begin{array}{l}\text { China } \\
\text { Italy }\end{array}$ & $\begin{array}{l}(101) \\
(102)\end{array}$ \\
\hline & 1 case report & Sedaghat et al. & Iran & (103) \\
\hline & 5 cases & Toscano et al. & Italy & (104) \\
\hline Miller-Fisher syndrome 1 & 1 case report & $\begin{array}{l}\text { Gutierrez-Ortiz } \\
\text { et al. }\end{array}$ & Spain & (115) \\
\hline $\begin{array}{l}\text { Neuropsychiatric } \\
\text { manifestations }\end{array}$ & 3 cases & Ferrando et al. & United States & (114) \\
\hline
\end{tabular}

Other neurological manifestations reported in COVID-19 patients include ataxia, acute hemorrhagic necrotizing encephalopathy, polyneuritis cranialis, and neuralgia (10, 81).

relationship between viral loads in the CNS and the severity of such manifestations are required, reducing the number of copies of SARS-CoV-2 in the circulation and tissues might be a useful strategy. Remdesivir is the only antiviral drug with demonstrated capacity to blocking SARS-CoV-2 replication in pre-clinical trials approved for usage in humans. This antiviral drug reduces the time of clinical recovery in patients with COVID-19 (116). The benefits of remdesivir for patients with neurological complications have not been evaluated. Other 
candidate agents that antagonize the activity of the host proteases implicated in the infection process of SARS-CoV-2 may be useful to limit the infective capacity of this virus. These include the camostat mesylate and nafamostat mesylate, two compounds that block the activity of TMPRSS2 $(19,117)$. The effects of these drugs on the severity and recovery of neurologic sequela associated with COVID-19 must be evaluated in future clinical trials. Passive immunization by transfer of convalescent human plasma may also contribute to reduce the viral loads and prevent or reverse the development of neurological symptoms. This assumption is supported by recent systematic reviews that found that convalescent plasma therapy improves symptoms, reduce viral loads, and diminishes mortality in COVID-19 patients (118). The time at which these proposed interventions would be more useful to counteract neurologic sequela of COVID-19 is unknown.

Immune-mediated neurotoxicity is an obvious therapeutic target for individuals with SARS-CoV-2 infection (59). The immune profile of patients with severe COVID-19 resembles the cytokine release syndrome (CRS) observed after CAR-Tcell therapy $(34,35)$. As aforementioned, individuals receiving CAR-T cells who develop CRS are at risk of injury to the nervous system. Therefore, lessons from the treatment of patients with CAR-T-cell-therapy-associated neurotoxicity might be applicable to COVID-19 patients. Tocilizumab, an antiIL-6 monoclonal antibody, is the primary treatment for CRS (119), and is currently being used to ameliorate inflammatory manifestations caused by SARS-CoV-2 infection (120). In patients with severe COVID-19, tocilizumab declined cytokine production and reduced the risk of intubation requirement (120). However, the utility of tocilizumab for management of CRSassociated neurotoxicity is controversial (121). Interestingly, mouse models have revealed that the antagonist of the receptor of IL-1 $\beta$ anakinra might be a better option than tocilizumab for the treatment of CRS and neurotoxicity after CAR-T-cell therapy (122). As a strong induction of IL-1 $\beta$ has been observed in severely ill COVID-19 patients (32), the potential use of anakinra deserves further investigation. Monocytes and macrophages also contribute to the development of CRS and neurotoxicity after CAR-T-cell therapy. As such, inhibition of GM-CSF with monoclonal antibodies has shown to reduce neuroinflammation in Phase I studies of patients receiving CAR-T-cell therapy (123). Interestingly, in a recent study conducted in patients with COVID-19, the GM-CSF blockade with mavrilimumab improved clinical symptoms, survival, and reduced intubation requirement (124). Inhibition of GM-CSF is thus a potential therapeutic for patients with COVID-19 that develop neurological complications. Short courses of steroids are safe and provide some benefits for the treatment of immune-mediated neurotoxicity. Specifically, dexamethasone may constitute a good candidate due to its excellent CNS penetration and beneficial effect on the integrity of the BBB. Dexamethasone has been safely used in patients with acute respiratory distress syndrome, reducing the requirement of mechanical ventilation and mortality (125). These data may support the use of dexamethasone for the management of neurological manifestations of SARS-CoV-2 infection, although possible consequences of the dexamethasoneinduced immunosuppression need to be evaluated.

The breaching of the $\mathrm{BBB}$ is an important event for the development of neurotoxicity in COVID-19 patients and individuals under CAR-T-cell therapy. Pharmacological agents targeting the $\mathrm{BBB}$ may thus be useful to treat severe neurological manifestations of COVID-19. The sonic hedgehog (SHH) signaling pathway is essential for the maintenance of integrity and immune homeostasis of the BBB (126). Agonists of $\mathrm{SHH}$, such as purmorphamine, a compound that activates the $\mathrm{SHH}$ by promoting smoothened protein (127), reduce $\mathrm{BBB}$ damage in animal models of infection and ischemic stroke (128-130). Although little evidence exists of the safety of purmorphamine in humans, this agent warrants further exploration for the management of neurotoxicity associated with severe infections, including COVID-19.

\section{IMPLICATIONS OF COVID-19 PANDEMIC FOR THE NEUROLOGY FIELD}

The magnitude of the current pandemic has generated concerns among professionals from various areas of medicine. The evidence summarized in this review shows that neurology is an active area of medicine at the frontline of the current pandemic. Actually, due to the increasing number of confirmed cases around the world and the neurotropic potential of SARS$\mathrm{CoV}-2$, it is highly likely that neurologists would have to provide medical care to patients with COVID-19, some of which might present neurological manifestations. The first and most important precautionary measure that must be taken by neurological centers around the world is to improve the knowledge of the disease among health care professionals. Obviously, measures of personal protection and social distancing should be extreme in neurology and neurosurgery clinics since it is possible that some COVID-19 patients attending with neurological symptoms with a not yet confirmed SARS-CoV-2 infection may constitute potential foci of inadvertent contagion for doctors, especially if they do not manifest respiratory symptoms initially. To prevent contagions, it is important to investigate previous contact with people with laboratoryconfirmed COVID-19 in patients attending to neurological centers. Similarly, it is crucial to maintain a high degree of clinical suspicion about possible SARS-CoV-2 infection in patients presenting an acute neurological condition. Furthermore, the continuous surveillance and intentional search for neurological complications in patients with confirmed SARS-CoV-2 infection are necessary and even mandatory because these measures could allow the timely establishment of therapeutic strategies for limiting neurologic sequelae.

Finally, the current pandemic may obligate some changes in normal care to patients with neurologic disorders at medical centers receiving many COVID-19 cases. Of particular importance is the possible impact of this pandemic in the triage and management of patients with stroke and other acute neurological emergencies due to resource re-allocation. Also, the interruption of activities at many neurology outpatient clinics 
may affect the management of chronic neurological conditions, requiring increased usage of tools such as telemedicine and e-care.

\section{CONCLUSIONS}

The clinical phenotype of COVID-19 encompasses a spectrum of neurological manifestations of varying severity that, besides respiratory symptoms, can cause high morbidity and mortality rates in individuals with SARS-CoV-2 infection. The current review constitutes a useful reference to improve our understanding of the pathophysiological mechanisms of SARS-CoV-2 infection and should motivate further studies about novel strategies to mitigate the impact of the current pandemic on the field of neurology.

\section{REFERENCES}

1. Zhu N, Zhang D, Wang W, Li X, Yang B, Song J, et al. A novel coronavirus from patients with pneumonia in China, 2019. N Engl J Med. (2020) 382:72733. doi: 10.1056/NEJMoa2001017

2. World Health Organization. Coronavirus Disease (COVID-2019) Situation Reports. Situation report - 192 (2020). Available online at: https://www.who. int/docs/default-source/coronaviruse/situation-reports/20200730-covid19- sitrep-192.pdf?sfvrsn=5e52901f_4 (accessed July 30, 2020).

3. Lee N, Hui D, Wu A, Chan P, Cameron P, Joynt GM, et al. A major outbreak of severe acute respiratory syndrome in Hong Kong. N Engl J Med. (2003) 348:1986-94. doi: 10.1056/NEJMoa030685

4. Guan WJ, Ni ZY, Hu Y, Liang WH, Ou CQ, He JX, et al. Clinical characteristics of coronavirus disease 2019 in China. N Engl J Med. (2020) 382:1708-20. doi: 10.1056/NEJMoa2002032

5. Huang C, Wang Y, Li X, Ren L, Zhao J, Hu Y, et al. Clinical features of patients infected with 2019 novel coronavirus in Wuhan, China. Lancet. (2020) 395:497-506. doi: 10.1016/S0140-6736(20)30183-5

6. Wang D, Hu B, Hu C, Zhu F, Liu X, Zhang J, et al. Clinical characteristics of 138 hospitalized patients with 2019 novel coronavirus-infected pneumonia in Wuhan, China. JAMA. (2020) 323:1061-9. doi: 10.1001/jama. 2020.1585

7. Richardson S, Hirsch JS, Narasimhan M, Crawford JM, Mcginn T, Davidson KW, et al. Presenting characteristics, comorbidities, and outcomes among 5700 patients hospitalized with COVID-19 in the New York city area. JAMA. (2020) 323:2052-9. doi: 10.1001/jama.2020.6775

8. Kanne JP, Little BP, Chung JH, Elicker BM, Ketai LH. Essentials for radiologists on COVID-19: an update-radiology scientific expert panel. Radiology. (2020) 296:200527. doi: 10.1148/radiol.2020200527

9. Baud D, Qi X, Nielsen-Saines K, Musso D, Pomar L, Favre G. Real estimates of mortality following COVID-19 infection. Lancet Infect Dis. (2020) 20:773. doi: 10.1016/S1473-3099(20)30195-X

10. Mao L, Jin H, Wang M, Hu Y, Chen S, He Q, et al. Neurologic manifestations of hospitalized patients with coronavirus disease 2019 in Wuhan, China. JAMA Neurol. (2020) 77:1-9. doi: 10.1001/jamaneurol.2020.1127

11. Lim YX, Ng YL, Tam JP, Liu DX. Human coronaviruses: a review of virushost interactions. Diseases. (2016) 4:26. doi: 10.3390/diseases4030026

12. Zaki AM, Van Boheemen S, Bestebroer TM, Osterhaus AD, Fouchier RA. Isolation of a novel coronavirus from a man with pneumonia in Saudi Arabia. N Engl J Med. (2012) 367:1814-20. doi: 10.1056/NEJMoa1211721

13. De Groot RJ, Baker SC, Baric RS, Brown CS, Drosten C, Enjuanes $\mathrm{L}$, et al. Middle East respiratory syndrome coronavirus. (MERS-CoV): announcement of the Coronavirus Study Group. J Virol. (2013) 87:7790-2. doi: 10.1128/JVI.01244-13

14. Andersen KG, Rambaut A, Lipkin WI, Holmes EC, Garry RF. The proximal origin of SARS-CoV-2. Nat Med. (2020) 26:450-52. doi: 10.1038/s41591-020-0820-9

\section{AUTHOR CONTRIBUTIONS}

PG-O, JC-P, and CS-M drafted the manuscript. FP-S, AR-N, and GG-Q are medical students from the Centro Especializado en Neurocirugía y Neurociencias México (CENNM) and the Escuela Nacional de Medicina y Homeopatía, Instituto Politécnico Nacional in Mexico City. They participated in the search for scientific literature and revised the paper for intellectual content. All authors read and approved the final version of the manuscript.

\section{ACKNOWLEDGMENTS}

We thank all of the medical staff of our center for their critical reading and commentary of our manuscript.

15. Zhou P, Yang X-L, Wang X-G, Hu B, Zhang L, Zhang W, et al. A pneumonia outbreak associated with a new coronavirus of probable bat origin. Nature. (2020) 579:270-3. doi: 10.1038/s41586-020-2012-7

16. Liu P, Chen W, Chen J-P. Viral metagenomics revealed sendai virus and coronavirus infection of Malayan pangolins (Manis javanica). Viruses. (2019) 11:979. doi: 10.3390/v11110979

17. Zhang T, Wu Q, Zhang Z. Probable pangolin origin of SARS-CoV2 associated with the COVID-19 outbreak. Curr Biol. (2020) 30:134651.e1342. doi: 10.1016/j.cub.2020.03.022

18. Li W, Moore MJ, Vasilieva N, Sui J, Wong SK, Berne MA, et al. Angiotensinconverting enzyme 2 is a functional receptor for the SARS coronavirus. Nature. (2003) 426:450-4. doi: 10.1038/nature02145

19. Hoffmann M, Kleine-Weber H, Schroeder S, Kruger N, Herrler T, Erichsen $\mathrm{S}$, et al. SARS-CoV-2 cell entry depends on ACE2 and TMPRSS2 and is blocked by a clinically proven protease inhibitor. Cell. (2020) 181:271-80.e8. doi: 10.1016/j.cell.2020.02.052

20. Walls AC, Park Y-J, Tortorici MA, Wall A, Mcguire AT, Veesler D. Structure, function, and antigenicity of the SARS-CoV-2 spike glycoprotein. Cell. (2020) 181:281-92.e6. doi: 10.1016/j.cell.2020.02.058

21. Glowacka I, Bertram S, Muller MA, Allen P, Soilleux E, Pfefferle S, et al. Evidence that TMPRSS2 activates the severe acute respiratory syndrome coronavirus spike protein for membrane fusion and reduces viral control by the humoral immune response. J Virol. (2011) 85:4122-34. doi: 10.1128/JVI.02232-10

22. Matsuyama S, Nao N, Shirato K, Kawase M, Saito S, Takayama I, et al. Enhanced isolation of SARS-CoV-2 by TMPRSS2-expressing cells. Proc Natl Acad Sci USA. (2020) 117:7001-3. doi: 10.1073/pnas.2002589117

23. Ou X, Liu Y, Lei X, Li P, Mi D, Ren L, et al. Characterization of spike glycoprotein of SARS-CoV-2 on virus entry and its immune cross-reactivity with SARS-CoV. Nat Commun. (2020) 11:1620. doi: 10.1038/s41467-020-15562-9

24. Zang R, Gomez Castro MF, Mccune BT, Zeng Q, Rothlauf PW, Sonnek NM, et al. TMPRSS2 and TMPRSS4 promote SARS-CoV-2 infection of human small intestinal enterocytes. Sci Immunol. (2020) 5:eabc3582. doi: 10.1126/sciimmunol.abc3582

25. Conti P, Ronconi G, Caraffa A, Gallenga CE, Ross R, Frydas I, et al. Induction of pro-inflammatory cytokines. (IL-1 and IL-6) and lung inflammation by Coronavirus-19. (COVI-19 or SARS-CoV-2): anti-inflammatory strategies. J Biol Regul Homeost Agents. (2020) 34: 327-31. doi: 10.23812/CONTI-E

26. Mcgonagle D, Sharif K, O'regan A, Bridgewood C. The role of cytokines including interleukin-6 in COVID-19 induced pneumonia and macrophage activation syndrome-like disease. Autoimmun Rev. (2020) 19:102537. doi: 10.1016/j.autrev.2020.102537

27. Wan S, Yi Q, Fan S, Lv J, Zhang X, Guo L, et al. Characteristics of lymphocyte subsets and cytokines in peripheral blood of 123 hospitalized patients with 2019 novel coronavirus pneumonia (NCP). MedRxiv [preprint]. (2020) doi: 10.1101/2020.02.10.20021832 
28. Yang Y, Shen C, Li J, Yuan J, Wei J, Wang F, et al. Plasma IP-10 and MCP-3 levels are highly associated with disease severity and predict the progression of COVID-19. J Allergy Clin Immunol. (2020) 146:119-27.e4. doi: 10.1016/j.jaci.2020.04.027

29. Sheahan T, Morrison TE, Funkhouser W, Uematsu S, Akira S, Baric RS, et al. MyD88 is required for protection from lethal infection with a mouse-adapted SARS-CoV. PLoS Pathog. (2008) 4:e1000240. doi: 10.1371/journal.ppat.1000240

30. Totura AL, Whitmore A, Agnihothram S, Schäfer A, Katze MG, Heise MT, et al. Toll-Like receptor 3 signaling via TRIF contributes to a protective innate immune response to severe acute respiratory syndrome coronavirus infection. mBio. (2015) 6:e00638-15. doi: 10.1128/mBio.00638-15

31. Shi CS, Nabar NR, Huang NN, Kehrl JH. SARS-coronavirus open reading frame- $8 \mathrm{~b}$ triggers intracellular stress pathways and activates NLRP3 inflammasomes. Cell Death Discov. (2019) 5:101. doi: 10.1038/s41420-019-0181-7

32. Ong EZ, Chan YFZ, Leong WY, Lee NMY, Kalimuddin S, Haja Mohideen SM, et al. A dynamic immune response shapes COVID-19 progression. Cell Host Microbe. (2020) 27:879-82.e2. doi: 10.1016/j.chom.2020. 03.021

33. Chen G, Wu D, Guo W, Cao Y, Huang D, Wang H, et al. Clinical and immunologic features in severe and moderate Coronavirus Disease 2019. J Clin Investig. (2020) 130:2620-9. doi: 10.1101/2020.02.16.20023903

34. Gust J, Hay KA, Hanafi LA, Li D, Myerson D, Gonzalez-Cuyar LF, et al. Endothelial activation and blood-brain barrier disruption in neurotoxicity after adoptive immunotherapy with CD19 CAR-T cells. Cancer Discov. (2017) 7:1404-19. doi: 10.1158/2159-8290.CD-17-0698

35. Santomasso BD, Park JH, Salloum D, Riviere I, Flynn J, Mead E, et al. Clinical and biological correlates of neurotoxicity associated with CAR T-cell therapy in patients with B-cell acute lymphoblastic leukemia. Cancer Discov. (2018) 8:958-71. doi: 10.1158/2159-8290.CD-17-1319

36. Wang W, Su B, Pang L, Qiao L, Feng Y, Ouyang Y, et al. High-dimensional immune profiling by mass cytometry revealed immunosuppression and dysfunction of immunity in COVID-19 patients. Cell Mol Immunol. (2020) 17:650-2. doi: 10.1038/s41423-020-0447-2

37. Diao B, Wang C, Tan Y, Chen X, Liu Y, Ning L, et al. Reduction and functional exhaustion of T cells in patients with coronavirus disease 2019 (COVID-19). Front Immunol. (2020) 11:827. doi: 10.3389/fimmu.2020.00827

38. Ono S, Tsujimoto H, Hiraki S, Aosasa S. Mechanisms of sepsis-induced immunosuppression and immunological modification therapies for sepsis. Ann Gastroenterol Surg. (2018) 2:351-8. doi: 10.1002/ags3.12194

39. Ding Y, He L, Zhang Q, Huang Z, Che X, Hou J, et al. Organ distribution of severe acute respiratory syndrome. (SARS) associated coronavirus. (SARS$\mathrm{CoV}$ ) in SARS patients: implications for pathogenesis and virus transmission pathways. J Pathol. (2004) 203:622-30. doi: 10.1002/path.1560

40. Gu J, Gong E, Zhang B, Zheng J, Gao Z, Zhong Y, et al. Multiple organ infection and the pathogenesis of SARS. J Exp Med. (2005) 202:415-24. doi: 10.1084/jem.20050828

41. Tian S, Xiong Y, Liu H, Niu L, Guo J, Liao M, et al. Pathological study of the 2019 novel coronavirus disease. (COVID-19) through postmortem core biopsies. Modern Pathol. (2020) 33:1007-14. doi: 10.1038/s41379-020-0536-X

42. Burks JS, Devald BL, Jankovsky LD, Gerdes JC. Two coronaviruses isolated from central nervous system tissue of two multiple sclerosis patients. Science. (1980) 209:933-4. doi: 10.1126/science.7403860

43. Fazzini E, Fleming J, Fahn S. Cerebrospinal fluid antibodies to coronavirus in patients with Parkinson's disease. Mov Disord. (1992) 7:153-8. doi: $10.1002 / \mathrm{mds} .870070210$

44. Murray RS, Brown B, Brian D, Cabirac GF. Detection of coronavirus RNA and antigen in multiple sclerosis brain. Ann Neurol. (1992) 31:525-33. doi: 10.1002/ana.410310511

45. Dessau RB, Lisby G, Frederiksen JL. Coronaviruses in spinal fluid of patients with acute monosymptomatic optic neuritis. Acta Neurol Scand. (1999) 100:88-91. doi: 10.1111/j.1600-0404.1999.tb01043.x

46. Hung EC, Chim SS, Chan PK, Tong YK, Ng EK, Chiu RW, et al. Detection of SARS coronavirus RNA in the cerebrospinal fluid of a patient with severe acute respiratory syndrome. Clin Chem. (2003) 49:2108-9. doi: $10.1373 /$ clinchem.2003.025437
47. Yeh EA, Collins A, Cohen ME, Duffner PK, Faden H. Detection of coronavirus in the central nervous system of a child with acute disseminated encephalomyelitis. Pediatrics. (2004) 113:e73-6. doi: 10.1542/peds.113.1.e73

48. Huang J, Zheng M, Tang X, Chen Y, Tong A, Zhou L. Potential of SARSCoV-2 to cause CNS infection: biologic fundamental and clinical experience. Front Neurol. (2020). 11:659. doi: 10.3389/fneur.2020.00659

49. Hamming I, Timens W, Bulthuis ML, Lely AT, Navis G, Van Goor H. Tissue distribution of ACE2 protein, the functional receptor for SARS coronavirus. A first step in understanding SARS pathogenesis. J Pathol. (2004) 203:631-7. doi: 10.1002/path.1570

50. Zou X, Chen K, Zou J, Han P, Hao J, Han Z. Single-cell RNA-seq data analysis on the receptor ACE2 expression reveals the potential risk of different human organs vulnerable to 2019-nCoV infection. Front Med. (2020) 14:185-92. doi: 10.1007/s11684-020-0754-0

51. Fan C, Li K, Ding Y, Lu WL, Wang J. ACE2 expression in kidney and testis may cause kidney and testis damage after 2019-nCoV infection. MedRxiv [preprint]. (2020). doi: 10.1101/2020.02.12.20022418

52. Xu H, Zhong L, Deng J, Peng J, Dan H, Zeng X, et al. High expression of ACE2 receptor of 2019-nCoV on the epithelial cells of oral mucosa. Int J Oral Sci. (2020) 12:8. doi: 10.1038/s41368-020-0074-x

53. Lin B, Ferguson C, White JT, Wang S, Vessella R, True LD, et al. Prostatelocalized and androgen-regulated expression of the membrane-bound serine protease TMPRSS2. Cancer Res. (1999) 59:4180-4.

54. Vaarala MH, Porvari KS, Kellokumpu S, Kyllönen AP, Vihko PT. Expression of transmembrane serine protease TMPRSS2 in mouse and human tissues. J Pathol. (2001) 193:134-40.

55. Bertram S, Dijkman R, Habjan M, Heurich A, Gierer S, Glowacka I, et al. TMPRSS2 activates the human coronavirus 229E for cathepsin-independent host cell entry and is expressed in viral target cells in the respiratory epithelium. J Virol. (2013) 87:6150-60. doi: 10.1128/JVI.03372-12

56. Muus C, Luecken MD, Eraslan G, Waghray A, Heimberg G, Sikkema L, et al. Integrated analyses of single-cell atlases reveal age, gender, and smoking status associations with cell type-specific expression of mediators of SARSCoV-2 viral entry and highlights inflammatory programs in putative target cells. bioRxiv [preprint]. (2020). doi: 10.1101/2020.04.19.049254

57. Xu J, Zhong S, Liu J, Li L, Li Y, Wu X, et al. Detection of severe acute respiratory syndrome coronavirus in the brain: potential role of the chemokine mig in pathogenesis. Clin Infect Dis. (2005) 41:1089-96. doi: $10.1086 / 444461$

58. Ding Y, Wang H, Shen H, Li Z, Geng J, Han H, et al. The clinical pathology of severe acute respiratory syndrome. (SARS): a report from China. J Pathol. (2003) 200:282-9. doi: 10.1002/path.1440

59. Mehta P, Mcauley DF, Brown M, Sanchez E, Tattersall RS, Manson JJ. COVID-19: consider cytokine storm syndromes and immunosuppression. Lancet. (2020) 395:1033-4. doi: 10.1016/S0140-6736(20)30628-0

60. Capaldo CT, Nusrat A. Cytokine regulation of tight junctions. Biochim Biophys Acta. (2009) 1788:864-71. doi: 10.1016/j.bbamem.2008.08.027

61. Kim KS. Mechanisms of microbial traversal of the blood-brain barrier. Nat Rev Microbiol. (2008) 6:625-34. doi: 10.1038/nrmicro1952

62. Baig AM, Khaleeq A, Ali U, Syeda H. Evidence of the COVID-19 virus targeting the CNS: tissue distribution, host-virus interaction, and proposed neurotropic mechanisms. ACS Chem Neurosci. (2020) 11:995-8. doi: 10.1021/acschemneuro.0c00122

63. Netland J, Meyerholz DK, Moore S, Cassell M, Perlman S. Severe acute respiratory syndrome coronavirus infection causes neuronal death in the absence of encephalitis in mice transgenic for human ACE2. J Virol. (2008) 82:7264-75. doi: 10.1128/JVI.00737-08

64. Dubé M, Le Coupanec A, Wong AHM, Rini JM, Desforges M, Talbot PJ. Axonal transport enables neuron-to-neuron propagation of human coronavirus OC43. J Virol. (2018) 92:e00404-18. doi: 10.1128/JVI.00404-18

65. Hwang CS. Olfactory neuropathy in severe acute respiratory syndrome: report of A case. Acta Neurol Taiwan. (2006) 15:26-8.

66. Lechien JR, Chiesa-Estomba CM, De Siati DR, Horoi M, Le Bon SD, Rodriguez A, et al. Olfactory and gustatory dysfunctions as a clinical presentation of mild-to-moderate forms of the coronavirus disease. (COVID-19): a multicenter European study. Eur Arch Otorhinolaryngol. (2020) 277:2251-61. doi: 10.1007/s00405-020-05965-1 
67. Li YC, Bai WZ, Hashikawa T. The neuroinvasive potential of SARS-CoV2 may play a role in the respiratory failure of COVID-19 patients. J Med Virol. (2020) 92:552-5. doi: 10.1002/jmv.25728

68. Matsuda K, Park CH, Sunden Y, Kimura T, Ochiai K, Kida H, et al. The vagus nerve is one route of transneural invasion for intranasally inoculated influenza a virus in mice. Vet Pathol. (2004) 41:101-7. doi: 10.1354/vp.41-2-101

69. Li YC, Bai WZ, Hirano N, Hayashida T, Taniguchi T, Sugita Y, et al. Neurotropic virus tracing suggests a membranous-coating-mediated mechanism for transsynaptic communication. J Comp Neurol. (2013) 521:203-12. doi: 10.1002/cne.23171

70. Chen N, Zhou M, Dong X, Qu J, Gong F, Han Y, et al. Epidemiological and clinical characteristics of 99 cases of 2019 novel coronavirus pneumonia in Wuhan, China: a descriptive study. Lancet. (2020) 395:507-13. doi: 10.1016/S0140-6736(20)30211-7

71. Pinzon RT, Wijaya VO, Buana RB, Al Jody A, Nunsio PN. Neurologic characteristics in coronavirus disease 2019 (COVID-19): a systematic review and meta-analysis. Front Neurol. (2020) 11:565. doi: 10.3389/fneur.2020.00565

72. Tsai ST, Lu MK, San S, Tsai CH. The neurologic manifestations of coronavirus disease 2019 pandemic: a systemic review. J Neurol. (2020) 11:1-9. doi: 10.3389/fneur.2020.00498

73. Porta-Etessam J, Matías-Guiu JA, González-García N, Gómez Iglesias P, Santos-Bueso E, Arriola-Villalobos P, et al. Spectrum of headaches associated with SARS-CoV-2 infection: study of healthcare professionals. Headache. (2020). doi: 10.1111/head.13902. [Epub ahead of print].

74. Morfopoulou S, Brown JR, Davies EG, Anderson G, Virasami A, Qasim W, et al. Human coronavirus OC43 associated with fatal encephalitis. N Engl J Med. (2016) 375:497-8. doi: 10.1056/NEJMc1509458

75. Arabi YM, Harthi A, Hussein J, Bouchama A, Johani S, Hajeer AH, et al. Severe neurologic syndrome associated with Middle East respiratory syndrome corona virus. (MERS-CoV). Infection. (2015) 43:495-501. doi: 10.1007/s15010-015-0720-y

76. Yin R, Feng W, Wang T, Chen G, Wu T, Chen D, et al. Concomitant neurological symptoms observed in a patient diagnosed with coronavirus disease 2019. J Med Virol. (2020). doi: 10.1002/jmv.25888. [Epub ahead of print].

77. Moriguchi T, Harii N, Goto J, Harada D, Sugawara H, Takamino J, et al. A first case of meningitis/encephalitis associated with SARS-coronavirus-2. Int J Infect Dis. (2020) 94:55-8. doi: 10.1016/j.ijid.2020.03.062

78. Duong $\mathrm{L}, \mathrm{Xu} \mathrm{P}$, Liu A. Meningoencephalitis without respiratory failure in a young female patient with COVID-19 infection in Downtown Los Angeles, early April 2020. Brain Behav Immun. (2020) 87:33. doi: 10.1016/j.bbi.2020.04.024

79. Filatov A, Sharma P, Hindi F, Espinosa PS. Neurological complications of coronavirus disease (COVID-19): encephalopathy. Cureus. (2020) 12:e7352. doi: 10.7759/cureus.7352

80. Ye M, Ren Y, Lv T. Encephalitis as a clinical manifestation of COVID-19. Brain Behav Immun. (2020) 88:945-6. doi: 10.1016/j.bbi.2020.04.017

81. Poyiadji N, Shahin G, Noujaim D, Stone M, Patel S, Griffith B. COVID-19-associated acute hemorrhagic necrotizing encephalopathy: CT and MRI features. Radiology. (2020) 296:E119-20. doi: 10.1148/radiol. 2020201187

82. Barnes M, Heywood AE, Mahimbo A, Rahman B, Newall AT, Macintyre CR. Acute myocardial infarction and influenza: a meta-analysis of case-control studies. Heart. (2015) 101:1738-47. doi: 10.1136/heartjnl-2015-307691

83. Gilden D, Cohrs RJ, Mahalingam R, Nagel MA. Varicella zoster virus vasculopathies: diverse clinical manifestations, laboratory features, pathogenesis, and treatment. Lancet Neurol. (2009) 8:731-40. doi: 10.1016/S1474-4422(09)70134-6

84. Helms J, Kremer S, Merdji H, Clere-Jehl R, Schenck M, Kummerlen C, et al. Neurologic features in severe SARS-CoV-2 infection. N Engl J Med. (2020) 382:2268-70. doi: 10.1056/NEJMc2008597

85. Oxley TJ, Mocco J, Majidi S, Kellner CP, Shoirah H, Singh IP, et al. Largevessel stroke as a presenting feature of Covid-19 in the young. $N$ Engl J Med. (2020) 382:e60. doi: 10.1056/NEJMc2009787

86. Trejo Gabriel Y Galán JM. Stroke as a complication and prognostic factor of COVID-19. Neurología. (2020) 35:318-22. doi: 10.1016/j.nrleng.2020.04.013
87. Levi M, Thachil J, Iba T, Levy JH. Coagulation abnormalities and thrombosis in patients with COVID-19. Lancet Haematol. (2020) 7:e438-40. doi: 10.1016/S2352-3026(20)30145-9

88. Inciardi RM, Lupi L, Zaccone G, Italia L, Raffo M, Tomasoni D, et al. Cardiac Involvement in a Patient With Coronavirus Disease 2019 (COVID-19). JAMA Cardiol. (2020) 5:1-6. doi: 10.1001/jamacardio.2020.1096

89. Sala S, Peretto G, Gramegna M, Palmisano A, Villatore A, Vignale D, et al. Acute myocarditis presenting as a reverse Tako-Tsubo syndrome in a patient with SARS-CoV-2 respiratory infection. Eur Heart J. (2020) 41:1861-2. doi: 10.1093/eurheartj/ehaa286

90. Tsai L-K, Hsieh S-T, Chao C-C, Chen Y-C, Lin Y-H, Chang S-C, et al. Neuromuscular disorders in severe acute respiratory syndrome. Arch Neurol. (2004) 61:1669-73. doi: 10.1001/archneur.61.11.1669

91. Brizzi KT, Lyons JL. Peripheral nervous system manifestations of infectious diseases. Neurohospitalist. (2014) 4:230-40. doi: 10.1177/1941874414535215

92. Giacomelli A, Pezzati L, Conti F, Bernacchia D, Siano M, Oreni L, et al. Self-reported olfactory and taste disorders in patients with severe acute respiratory coronavirus 2 infection: a cross-sectional study. Clin Infect Dis. (2020) 71:889-90. doi: 10.1093/cid/ciaa330

93. Beltrán-Corbellini Á, Chico-García JL, Martínez-Poles J, RodríguezJorge F, Natera-Villalba E, Gómez-Corral J, et al. Acute-onset smell and taste disorders in the context of COVID-19: a pilot multicentre polymerase chain reaction based case-control study. Eur J Neurol. (2020). doi: 10.1111/ene.14273. [Epub ahead of print].

94. Lorenzo Villalba N, Maouche Y, Alonso Ortiz MB, Cordoba Sosa Z, Chahbazian JB, Syrovatkova A, et al. Anosmia and dysgeusia in the absence of other respiratory diseases: should COVID-19 infection be considered? Eur J Case Rep Internal Med. (2020) 7:001641. doi: 10.12890/2020_001641

95. Spinato G, Fabbris C, Polesel J, Cazzador D, Borsetto D, Hopkins C, et al. Alterations in smell or taste in mildly symptomatic outpatients with SARSCoV-2 infection. JAMA. (2020) 323:2089-90. doi: 10.1001/jama.2020.6771

96. Yan CH, Faraji F, Prajapati DP, Ostrander BT, Deconde AS. Self-reported olfactory loss associates with outpatient clinical course in COVID-19. Int Forum Allergy Rhinol. (2020) 10:821-31. doi: 10.1002/alr.22592

97. Wakerley BR, Yuki N. Infectious and noninfectious triggers in Guillain-Barré syndrome. Expert Rev Clin Immunol. (2013) 9:627-39. doi: 10.1586/1744666X.2013.811119

98. Jacobs BC, Rothbarth PH, Van Der Meché FG, Herbrink P, Schmitz PI, De Klerk MA, et al. The spectrum of antecedent infections in Guillain-Barré syndrome: a case-control study. Neurology. (1998) 51:1110-5. doi: 10.1212/WNL.51.4.1110

99. Brasil P, Sequeira PC, Freitas ADA, Zogbi HE, Calvet GA, De Souza RV, et al. Guillain-Barré syndrome associated with Zika virus infection. Lancet. (2016) 387:1482. doi: 10.1016/S0140-6736(16)30058-7

100. Kim JE, Heo JH, Kim HO, Song SH, Park SS, Park TH, et al. Neurological complications during treatment of middle east respiratory syndrome. J Clin Neurol. (2017) 13:227-33. doi: 10.3988/jcn.2017.13.3.227

101. Zhao H, Shen D, Zhou H, Liu J, Chen S. Guillain-Barré syndrome associated with SARS-CoV-2 infection: causality or coincidence? Lancet Neurol. (2020) 19:383-4. doi: 10.1016/S1474-4422(20)30109-5

102. Alberti P, Beretta S, Piatti M, Karantzoulis A, Piatti ML, Santoro P, et al. Guillain-Barré syndrome related to COVID-19 infection. Neurol Neuroimmunol Neuroinflamm. (2020) 7:e741. doi: 10.1212/NXI.0000000000000741

103. Sedaghat Z, Karimi N. Guillain Barre syndrome associated with COVID-19 infection: a case report. J Clin Neurosci. (2020) 76:233-5. doi: 10.1016/j.jocn.2020.04.062

104. Toscano G, Palmerini F, Ravaglia S, Ruiz L, Invernizzi P, Cuzzoni MG, et al. Guillain-Barré Syndrome associated with SARS-CoV-2. N Engl J Med. (2020) 382:2574-6. doi: 10.1056/NEJMc2009191

105. Sheikh KA, Ho TW, Nachamkin I, Li CY, Cornblath DR, Asbury AK, et al. Molecular mimicry in Guillain-Barré syndrome. Ann N Y Acad Sci. (1998) 845:307-21. doi: 10.1111/j.1749-6632.1998.tb09683.x

106. Ang CW, Laman JD, Willison HJ, Wagner ER, Endtz HP, De Klerk MA, et al. Structure of Campylobacter jejuni lipopolysaccharides determines antiganglioside specificity and clinical features of GuillainBarré and Miller Fisher patients. Infect Immun. (2002) 70:1202-8. doi: 10.1128/IAI.70.3.1202-1208.2002 
107. Kusunoki S, Shiina M, Kanazawa I. Anti-Gal-C antibodies in GBS subsequent to mycoplasma infection: evidence of molecular mimicry. Neurology. (2001) 57:736-8. doi: 10.1212/WNL.57.4.736

108. Manjunatha N, Math SB, Kulkarni GB, Chaturvedi SK. The neuropsychiatric aspects of influenza/swine flu: a selective review. Ind Psychiatry J. (2011) 20:83-90. doi: 10.4103/0972-6748.102479

109. Cheng SK, Tsang JS, Ku KH, Wong CW, Ng YK. Psychiatric complications in patients with severe acute respiratory syndrome. (SARS) during the acute treatment phase: a series of 10 cases. Br J Psychiatry. (2004) 184:359-60. doi: 10.1192/bjp.184.4.359

110. Lee DTS, Wing YK, Leung HCM, Sung JJY, Ng YK, Yiu GC, et al. Factors associated with psychosis among patients with severe acute respiratory syndrome: a case-control study. Clin Infect Dis. (2004) 39:1247-9. doi: $10.1086 / 424016$

111. Rogers JP, Chesney E, Oliver D, Pollak TA, Mcguire P, Fusar-Poli $\mathrm{P}$, et al. Psychiatric and neuropsychiatric presentations associated with severe coronavirus infections: a systematic review and meta-analysis with comparison to the COVID-19 pandemic. Lancet Psychiatry. (2020) 7:611-27. doi: 10.1016/S2215-0366(20)30203-0

112. Upthegrove R, Khandaker GM. Cytokines, oxidative stress and cellular markers of inflammation in schizophrenia. Curr Top Behav Neurosci. (2020) 44:49-66. doi: 10.1007/7854_2018_88

113. Troyer EA, Kohn JN, Hong S. Are we facing a crashing wave of neuropsychiatric sequelae of COVID-19? Neuropsychiatric symptoms and potential immunologic mechanisms. Brain Behav Immunity. (2020) 87:34-9. doi: 10.1016/j.bbi.2020.04.027

114. Ferrando SJ, Klepacz L, Lynch S, Tavakkoli M, Dornbush R, Baharani R, et al. COVID-19 psychosis: a potential new neuropsychiatric condition triggered by novel coronavirus infection and the inflammatory response? Psychosomatics. (2020). doi: 10.1016/j.psym.2020.05.012. [Epub ahead of print].

115. Gutiérrez-Ortiz C, Méndez A, Rodrigo-Rey S, San Pedro-Murillo E, Bermejo-Guerrero L, Gordo-Mañas R, et al. Miller Fisher Syndrome and polyneuritis cranialis in COVID-19. Neurology. (2020) 95:e601-5. doi: 10.1212/WNL.0000000000009619

116. Beigel JH, Tomashek KM, Dodd LE, Mehta AK, Zingman BS, Kalil AC, et al. Remdesivir for the treatment of Covid-19 - preliminary report. $N$ Engl J Med. (2020). doi: 10.1056/NEJMoa2007764

117. Hoffmann M, Schroeder S, Kleine-Weber H, Müller MA, Drosten C, Pöhlmann S. Nafamostat mesylate blocks activation of SARS-CoV-2: new treatment option for COVID-19. Antimicrob Agents Chemother. (2020) 64:e00754-20. doi: 10.1128/AAC.00754-20

118. Rajendran K, Krishnasamy N, Rangarajan J, Rathinam J, Natarajan M, Ramachandran A. Convalescent plasma transfusion for the treatment of COVID-19: systematic review. J Med Virol. (2020). doi: 10.1002/jmv. 25961

119. Kotch C, Barrett D, Teachey DT. Tocilizumab for the treatment of chimeric antigen receptor T cell-induced cytokine release syndrome. Expert Rev Clin Immunol. (2019) 15:813-22. doi: 10.1080/1744666X.2019.1629904

120. Alattar R, Ibrahim TBH, Shaar SH, Abdalla S, Shukri K, Daghfal JN, et al. Tocilizumab for the treatment of severe coronavirus disease 2019. J Med Virol. (2020). doi: 10.1002/jmv.25964
121. Teachey DT, Bishop MR, Maloney DG, Grupp SA. Toxicity management after chimeric antigen receptor T cell therapy: one size does not fit 'ALL'. Nat Rev Clin Oncol. (2018) 15:218. doi: 10.1038/nrclinonc.2018.19

122. Norelli M, Camisa B, Barbiera G, Falcone L, Purevdorj A, Genua M, et al. Monocyte-derived IL-1 and IL-6 are differentially required for cytokinerelease syndrome and neurotoxicity due to CAR T cells. Nat Med. (2018) 24:739-48. doi: 10.1038/s41591-018-0036-4

123. Sterner RM, Sakemura R, Cox MJ, Yang N, Khadka RH, Forsman $\mathrm{CL}$, et al. GM-CSF inhibition reduces cytokine release syndrome and neuroinflammation but enhances CAR-T cell function in xenografts. Blood. (2019) 133:697-709. doi: 10.1182/blood-2018-10-881722

124. De Luca G, Cavalli G, Campochiaro C, Della-Torre E, Angelillo P, Tomelleri A, et al. GM-CSF blockade with mavrilimumab in severe COVID-19 pneumonia and systemic hyperinflammation: a singlecentre, prospective cohort study. Lancet Rheumatol. (2020) 2:E465-73. doi: 10.1016/S2665-9913(20)30170-3

125. Villar J, Ferrando C, Martínez D, Ambrós A, Muñoz T, Soler JA, et al. Dexamethasone treatment for the acute respiratory distress syndrome: a multicentre, randomised controlled trial. Lancet Respir Med. (2020) 8:26776. doi: 10.1016/S2213-2600(19)30417-5

126. Alvarez JI, Dodelet-Devillers A, Kebir H, Ifergan I, Fabre PJ, Terouz $\mathrm{S}$, et al. The Hedgehog pathway promotes blood-brain barrier integrity and CNS immune quiescence. Science. (2011) 334:1727-31. doi: $10.1126 /$ science. 1206936

127. Sinha S, Chen JK. Purmorphamine activates the Hedgehog pathway by targeting Smoothened. Nat Chem Biol. (2006) 2:29-30. doi: $10.1038 /$ nchembio753

128. Chechneva OV, Mayrhofer F, Daugherty DJ, Krishnamurty RG, Bannerman $\mathrm{P}$, Pleasure DE, et al. A Smoothened receptor agonist is neuroprotective and promotes regeneration after ischemic brain injury. Cell Death Dis. (2014) 5:e1481. doi: 10.1038/cddis.2014.446

129. Singh VB, Singh MV, Gorantla S, Poluektova LY, Maggirwar SB. Smoothened agonist reduces human immunodeficiency virus type-1-induced bloodbrain barrier breakdown in humanized mice. Sci Rep. (2016) 6:26876. doi: 10.1038/srep26876

130. Liu D, Bai X, Ma W, Xin D, Chu X, Yuan H, et al. Purmorphamine attenuates neuro-inflammation and synaptic impairments after hypoxicischemic injury in neonatal mice via shh signaling. Front Pharmacol. (2020) 11:204. doi: 10.3389/fphar.2020.00204

Conflict of Interest: The authors declare that the research was conducted in the absence of any commercial or financial relationships that could be construed as a potential conflict of interest.

Copyright (c) 2020 Guadarrama-Ortiz, Choreño-Parra, Sánchez-Martínez, PachecoSánchez, Rodríguez-Nava and García-Quintero. This is an open-access article distributed under the terms of the Creative Commons Attribution License (CC BY). The use, distribution or reproduction in other forums is permitted, provided the original author(s) and the copyright owner(s) are credited and that the original publication in this journal is cited, in accordance with accepted academic practice. No use, distribution or reproduction is permitted which does not comply with these terms. 